\title{
Effect of vulcanization system and carbon black on mechanical and swelling properties of EPDM blends
}

\author{
Hesty Eka Mayasari*, Arum Yuniari \\ Center for Leather, Rubber and Plastics, Jl. Sokonandi No. 9 Yogyakarta, 55166, Indonesia \\ *Coresponding author. Telp.: +62 274 512929, 563939, Fax.: +62 274563655 \\ E-mail: hesty.ekamayasari@yahoo.com
}

Received: 28 January 2016 Revised: 18 May 2016 Accepted: 20 May 2016

\begin{abstract}
EPDM (Ethylene propylene diene monomer) is one of synthetic rubber that widely used in automotive. It must be vulcanized and added by other materials before used. The aim of this study is to investigate the effect of vulcanization system and the addition of carbon black (CB) to the mechanical properties and swelling characteristic of EPDM. This research used three vulcanization system: conventional vulcanization (CV), efficient vulcanization (EV), and semi-efficient vulcanization (SEV) with the variation of carbon black 50, 60, and $70 \mathrm{phr}$ (per hundred resin). This research showed that EV system resulted faster vulcanization time and lower delta torque than SEV and CV systems. This system also performed the highest tensile strength, elongation, and tear strength, while SEV system resulted the highest hardness. Furthermore, the conventional vulcanization system resulted the lowest swelling index.
\end{abstract}

Keywords: vulcanization system, EPDM, efficient, semi-efficient, conventional.

\section{INTRODUCTION}

Ethylene-Propylene-Diene-Rubber (EPDM) is a type of synthetic rubber which has a good resistance to chemical, weathering, and aging. EPDM is widely used in automotive. EPDM is obtained by polymerizing ethylene and propylene with a little amount of a diene. Sulphur vulcanization in EPDM allowed by the diene-monomers in the main chain (Dijkhuis et al., 2009; Nabil et al., 2013).

Sulphur is one of vulcanizing agent and plays an important role in the process of vulcanization. Sulphur vulcanization systems are classified as efficient (EV), semi-efficient (SEV), and conventional (CV). Efficient vulcanization system (EV) is characterized by a high ratio of accelerators to sulphur $(>2.5)$ which produces a high percentage of monosulfidic in the formation of the crosslink. Conventional vulcanization system (CV) has a low ratio of accelerators to sulphur ( 0.1 to 0.6 ), which produces a high percentage of polysulfidic, while the semi-efficient vulcanization system (SEV) is in between of them, which is characterized by the moderate ratio of accelerators to sulphur ( 0.7 to 2.5) (Dijkhuis et al., 2009). Yuniari et al. (2013) found that the different sulphur loading gave different result for the vulcanizate. Some vulcanization systems; conventional (CV), efficient (EV) also affected on the process of thermal degradation (Yahya et al., 2011).

Some additional materials such as filler, accelerator, vulcanization agent, activator, antioxidant, and softener are added during the vulcanization process to improve the properties of the vulcanizate. Carbon black (CB), the most widely used filler in rubber industry is a reinforcing filler. It is applied in rubber to improve strength and mechanical properties of the vulcanizates. The surface of $\mathrm{CB}$ can absorb the rubber molecules, it can increase the formation of bound rubber (Hasan et al., 2012). The formation of crosslink between EPDM and carbon black depend on the type and amount of carbon black. The amount of filler affect the tensile strength and the curing characteristics of elastomer (Litinov et al., 2011; Formela \& Haponiuk, 2014). The relationship between the crosslink density, network structure and mechanical properties of CB reinforced EPDM had been investigated by Dijkhuis et al. (2009).

Accelerator is used to accelerate the vulcani- 
zation process and improve the properties of the vulcanizate. Accelerator can be used a single or binary system. However, the usage of binary accelerator is preferable because the combination system of accelerator showed higher activity than a single accelerator separately (Indrajati \& Sholeh, 2014).

This study will evaluate the effect of the vulcanization system (CV, SEV, EV) and $\mathrm{CB}$ addition on EPDM in order to determine the best vulcanization system and CB loading to produce the desired product.

\section{MATERIALS AND METHODS \\ Materials}

Synthetic rubber EPDM Keltan 4551 A was used in this study. The additive materials used were CB N220 (Ex. Korea) as a filler, paraffin wax Antilux 654 A and TMQ as antioxidants, paraffinic oil as a softener, zinc oxide $(\mathrm{ZnO}) \mathrm{Ex}$. Indoxide and stearic acid Aflux $42 \mathrm{M}$ as activators, tetramethylthiuram disulphide (TMTD) and mercaptobenzothiazole (MBT) as accelerators, and sulphur Ex. Miwon as a vulcanization agent. The formulation used in this study are presented in Table 1.

\section{Methods}

Equipment used in this study were two roll mills (modified with a capacity of $2 \mathrm{~kg}$ ), Toyoseiki A-652 200500 hydraulic press, Kao Tieh tensile strength tester, Gotech 3000A moving die rheometer (MDR), and Tecklock hardness tester.
Compounds were made by mixed the materials using two roll mills equipment with time taken and sequence show on Table 2.

After homogeneous blend was reached, the compounds were taken out from two roll mills then cooled and stored in conditions $23 \pm 2{ }^{\circ} \mathrm{C}$ for $24 \mathrm{~h}$. The compounds were vulcanized by compression molding in $170^{\circ} \mathrm{C}$ and $150 \mathrm{~kg} / \mathrm{cm}^{2}$, the duration of vulcanization was determined by rheometer.

The cure characteristics were obtained using a rheometer, which was used to determine the scorch time $\left(\mathrm{ts}_{2}\right)$, cure time $\left(\mathrm{t}_{90}\right)$, cure rate index (CRI), maximum torque $(\mathrm{mH})$, minimum torque $(\mathrm{mL})$. Cure rate index (CRI) calculated based on the difference of the optimum time with scorch time according to equation (1). Maximum torque and minimum torque are used to calculate delta torque by equation (2)

$\mathrm{CRI}=100 /\left(\mathrm{t}_{90}-\mathrm{ts}_{2}\right)$

Delta torque $=\mathrm{mH}-\mathrm{mL}$

Tests conducted on vulcanizates were tensile strength and elongation at break according to ISO 37 , hardness according to ISO 48, and tear strength according to ISO 34.

Swelling test was performed for $72 \mathrm{~h}$ at $23 \pm 2^{\circ} \mathrm{C}$ according to ISO 1817 . The change in mass was calculated by equation (3).

Swelling index $(\%)=\left[\left(\mathrm{W}_{1}-\mathrm{W}_{0}\right) / \mathrm{W}_{0}\right] \times 100$

Where $\mathrm{W}_{1}$ is the mass of test piece after swelling, $\mathrm{W}_{0}$ is the mass of test piece before swelling.

Table 1. Formulation of rubber vulcanizates with various vulcanization systems and carbon black loading.

\begin{tabular}{|c|c|c|c|c|c|c|c|c|c|}
\hline \multirow{3}{*}{ Materials } & \multicolumn{3}{|c|}{ EV } & \multicolumn{3}{|c|}{ SEV } & \multicolumn{3}{|c|}{$\mathrm{CV}$} \\
\hline & ET1 & ET2 & ET3 & ST1 & ST2 & ST3 & CT1 & CT2 & CT3 \\
\hline & phr & phr & phr & phr & phr & phr & phr & phr & phr \\
\hline EPDM & 100 & 100 & 100 & 100 & 100 & 100 & 100 & 100 & 100 \\
\hline Carbon black (N220) & 50 & 60 & 70 & 50 & 60 & 70 & 50 & 60 & 70 \\
\hline $\mathrm{ZnO}$ & 5 & 5 & 5 & 5 & 5 & 5 & 5 & 5 & 5 \\
\hline Stearic acid & 1 & 1 & 1 & 1 & 1 & 1 & 1 & 1 & 1 \\
\hline TMQ & 1 & 1 & 1 & 1 & 1 & 1 & 1 & 1 & 1 \\
\hline Paraffin wax & 0.5 & 0.5 & 0.5 & 0.5 & 0.5 & 0.5 & 0.5 & 0.5 & 0.5 \\
\hline Paraffinic oil & 5 & 5 & 5 & 5 & 5 & 5 & 5 & 5 & 5 \\
\hline TMTD & 1 & 1 & 1 & 1.4 & 1.4 & 1.4 & 0.75 & 0.75 & 0.75 \\
\hline MBT & 1 & 1 & 1 & 1 & 1 & 1 & 0.5 & 0.5 & 0.5 \\
\hline Sulphur & 0.8 & 0.8 & 0.8 & 1.7 & 1.7 & 1.7 & 2.5 & 2.5 & 2.5 \\
\hline
\end{tabular}


Table 2. Time taken and sequence of EPDM vulcanizates.

\begin{tabular}{lc}
\hline \multicolumn{1}{c}{ Ingredients } & Time (approximately), min \\
\hline EPDM & 5 \\
ZnO & 4 \\
Stearic acid & 4 \\
Carbon black + paraffinic oil & 9 \\
TMQ & 3 \\
Paraffin wax & 2 \\
TMTD and MBT & 2 \\
Sulphur & 3 \\
\hline Total & 32 \\
\hline
\end{tabular}

\section{RESULTS AND DISCUSSION \\ Curing Characteristics}

The important parameters of the vulcanization process such as the optimum time $\left(\mathrm{t}_{90}\right)$, scorch time $\left(\mathrm{ts}_{2}\right)$, cure rate index (CRI), and torque of the vulcanizate can be known from the rheometer. The optimum time $\left(t_{90}\right)$ is the time to cure vulcanizate $90 \%$. Scorch time $\left(\mathrm{ts}_{2}\right)$ is an indicator of the processing safety. Curing characteristics of vulcanizates are presented in Table 3.

The fastest optimum vulcanization time $\left(t_{90}\right)$ and the highest CRI have resulted from EV vulcanization system, then SEV and CV. These results are consistent with the research conducted by Minnath et al. (2011), the increasing of CRI is proportional to the decreasing of vulcanization reaction time. This is because the EV system has $2.5 \mathrm{phr}$ ratio accelerator to sulphur, which contains at least $0.8 \mathrm{phr}$ sulphur and more accelerator. Thus, the time required for the formation of crosslink between EPDM with sulphur become short, so that the curing time is the fastest. Then,

Table 3. Curing characteristics of EPDM vulcanizates.

\begin{tabular}{lccc}
\hline \multicolumn{1}{c}{ Code } & $\mathrm{ts}_{2}, \mathrm{~s}$ & $\mathrm{t}_{90}, \mathrm{~s}$ & CRI, s$^{-1}$ \\
\hline EV 50 phr & 36 & 265 & 0.44 \\
EV 60 phr & 33 & 302 & 0.37 \\
EV 70 phr & 38 & 307 & 0.37 \\
SEV 50 phr & 31 & 381 & 0.29 \\
SEV 60 phr & 28 & 436 & 0.24 \\
SEV 70 phr & 27 & 422 & 0.25 \\
CV 50 phr & 32 & 1036 & 0.10 \\
CV 60 phr & 36 & 1591 & 0.06 \\
CV 70 phr & 36 & 1742 & 0.06 \\
\hline
\end{tabular}

the SEV vulcanization system with an amount of sulphur as $1.7 \mathrm{phr}$, and CV vulcanization system with an amount of sulphur as $2.5 \mathrm{phr}$. The increasing amount of sulphur loading increasing the time needed to form the crosslink. Table 2 shows that the optimum time will increase with the increasing of $\mathrm{CB}$ content. This phenomena possibly state that the more $\mathrm{CB}$ added, the more time was needed to absorb the rubber molecules to its surface.

Fig. 1 shows that the EV system gives the lowest delta torque, then SEV and CV. According to the research conducted by Dijkhuis et al. (2009), increasing the amount of CB proportional to the increasing of the delta torque. The density of crosslinking increase with the increasing of the number of $\mathrm{CB}$, which is the bonding between polymer with $\mathrm{CB}$ can increase the torque (Li et al., 2008). Torque is the amount of force needed in compounding process. Therefore, the delta torque would be proportionate with the curing time, the amount of sulphur and the amount of $\mathrm{CB}$ addition.

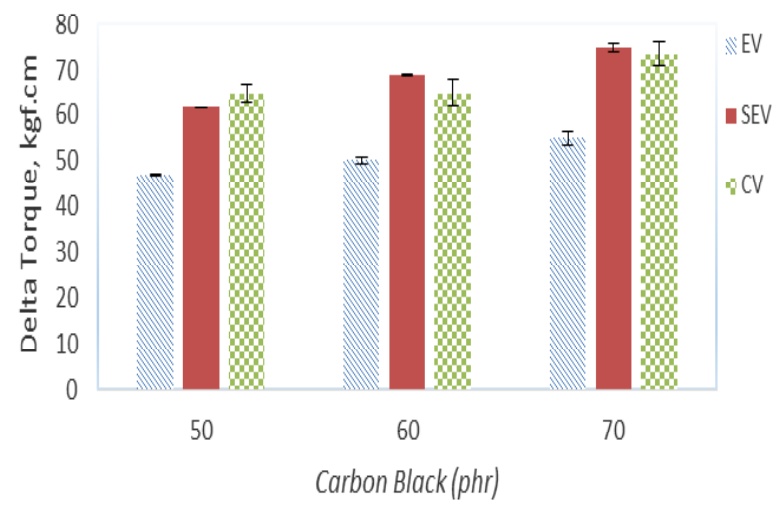

Fig. 1. Effect of vulcanization systems and carbon black on torque. 


\section{Mechanical Properties of EPDM Vulcanizate}

The mechanical properties of the vulcanizate are very important to be known because it is associated with the quality of rubber products. Mechanical properties are presented in Fig. 2-6.

\section{Hardness of EPDM vulcanizate}

Hardness is one of the requirements needed in the manufacture of engineering products. Hardness of the vulcanizate depends on the hardness of components (Yuniari et al., 2013). Fig. 2 shows the minimum hardness obtained from the EV vulcanization system. While the results of SEV and $\mathrm{CV}$ vulcanization system have not much difference. The previous study by Dijkhuis et al. (2009) got that the hardness from EV lower than SEV and CV. Hardness increases with the increasing amount of crosslink. Yuniari et al. (2013) also got the same results, hardness increases with the increasing amount of sulphur. This happens because the high density crosslink showed the tightly of that material molecules so that it more rigid and hard.

The vulcanizate's hardness increases with the increasing of $\mathrm{CB}$ loading. The increasing of hardness possibly due to $\mathrm{CB}$ as a reinforcing filler (strengthening the mechanical properties). The surface area of $\mathrm{CB}$ takes effect on hardness because its outer surface allows the bond formation of and keep the bound not moving. The increasing of $\mathrm{CB}$ make the space on the rubber become full so that the rubber vulcanizate becomes stiffer (Hasan et al., 2011).

\section{Tensile strength of EPDM vulcanizate}

Tensile strength is statically mechanical testing by means of samples drawn by the load. The

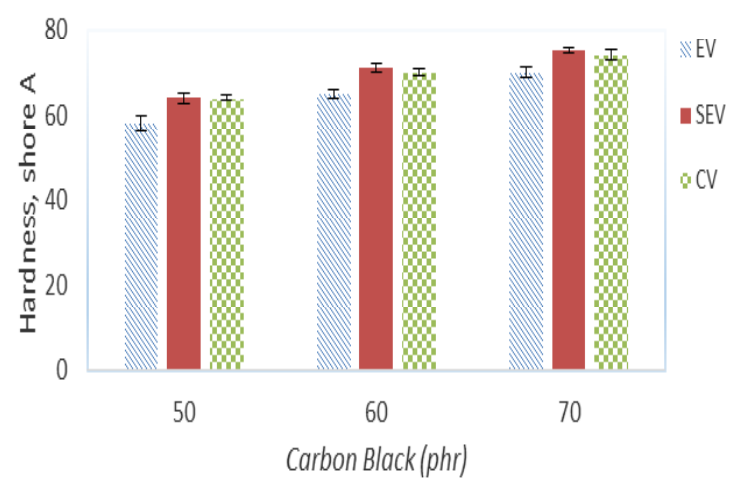

Fig. 2. Effect of vulcanization system and carbon black on hardness. tensile strength of vulcanizate is presented in Fig. 3 . The lowest tensile strength has resulted from $\mathrm{CV}$ vulcanization system, then SEV and then $\mathrm{EV}$, as the previous study conducted by Dijkhuis et al. (2009). Tensile strength increases with the increasing of the crosslink density, but at an optimum level of filler, it will decrease (Dijkhuis et al., 2009; Li et al., 2008). Vulcanization system and the type of rubber determine the formation of the crosslink density. High crosslink density indicates that the material is tight and rigid, so the elasticity and tensile strength decrease.

Tensile strength increases with the addition of $\mathrm{CB}$, but at some point, it will decrease. Increasing the number of bounds between the $\mathrm{CB}$ and the rubber molecules can increase the tensile strength (Li et al., 2008) and the increasing of hardness can decrease the tensile strength of vulcanizate (Hasan et al., 2011).

\section{Elongation of EPDM vulcanizate}

Elongation is interpreted as the resistance of material to elastic deformation (Yuniari et al., 2013). Fig. 4 shows that the lowest elongation has resulted from CV vulcanization system. These results are consistent with the previous study conducted by Dijkhuis et al. (2009). The elongation of EPDM vulcanizates proportionate with the tensile strength. Elongation decreases with the increasing of crosslink density because the greater amount of crosslink make the material more difficult to be stretched (Dijkhuis et al., 2009). EV vulcanization system produces higher elongation at break than SEV and CV. EV vulcanization system with the high amount of accelerator result more monosulfidic bonding (Ahmed et al., 2012).

Elongation decreases with the addition of

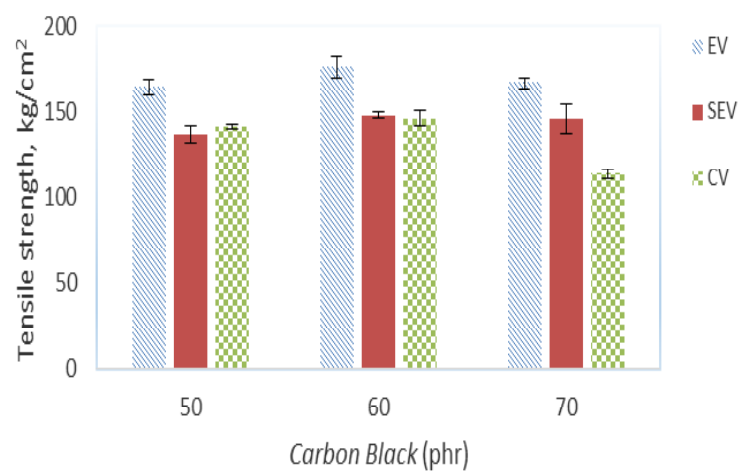

Fig. 3. Effect of vulcanization systems and carbon black on tensile strength. 


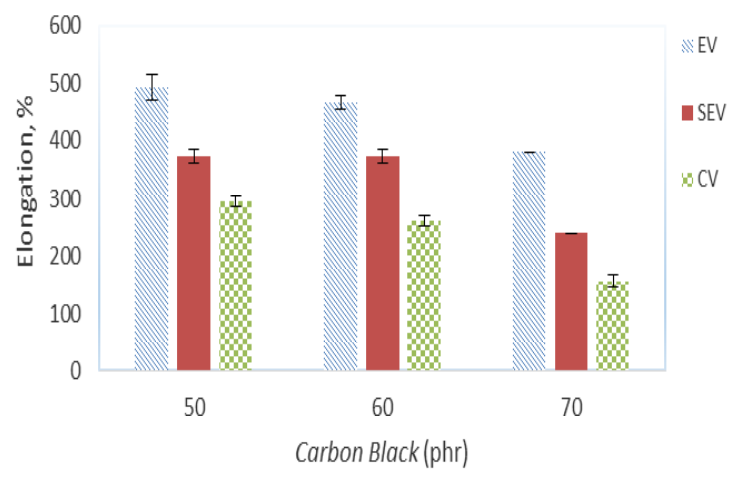

Fig. 4. Effect of vulcanization systems and carbon black on elongation of EPDM.

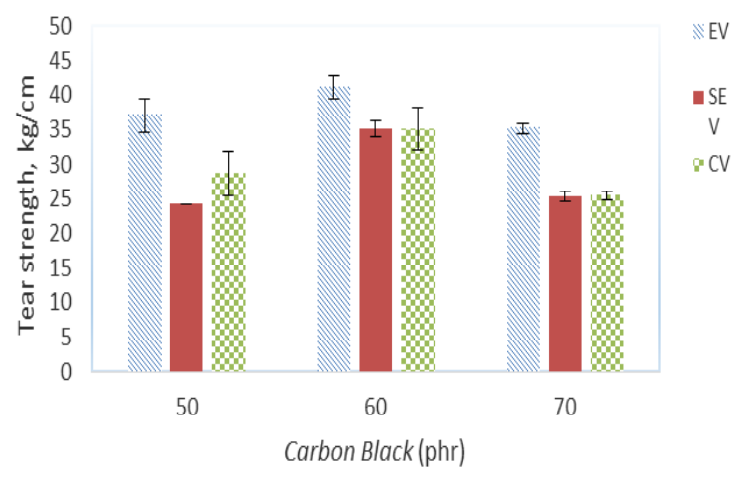

Fig. 5. Effect of vulcanization systems and carbon black addition on tear strength.

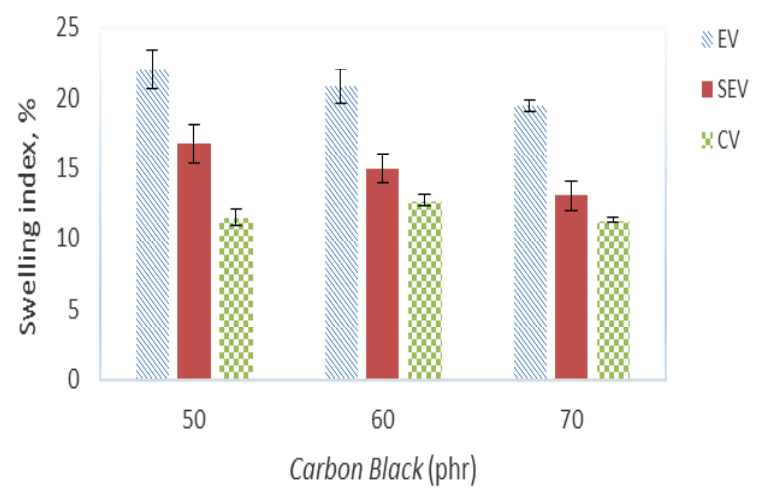

Fig. 6. Effect of vulcanization systems and carbon black on swelling index.

CB. The amount of CB makes vulcanizates stiffer so that the elasticity and tensile strength decrease (Li et al., 2008).

\section{Tear Strength of EPDM Vulcanizate}

Tear strength of the vulcanizate proportionate with the elongation properties. Fig. 5 shows the highest tear strength has resulted from EV vulcanization system. Generally, tear strength is correlated with the amount of polysulfidic crosslink, while monosulfidic crosslink produces more brittle vulcanization. This study give same result with the studied by Dijkhuis et al. (2009) where the polysulfidic crosslink didn't show a big effect on the material tear strength.

Tear strength increases from the addition of $50 \mathrm{phr}$ to $60 \mathrm{phr}$ and then decreases at the addition of $70 \mathrm{phr}$ of CB. The increasing of stiffness makes the vulcanizate more difficult to be ripped so that the tear strength increases (Hasan et al., 2011). However, at a certain point, vulcanizate will be fatigue, so that it will easy to be ripped.

\section{Swelling characteristics of EPDM vulcanizate}

Swelling occurs because of the expansion of polymer and the availability of more free volume to facilitate the mass transfer of solvent (Yuniari \& Sarengat, 2013).

Vulcanization system is closely related to the formation of crosslink density. Fig. 6 shows that the EV vulcanization system produces higher swelling index than the SEV and CV vulcanization system. Swelling index is correlated with the crosslink density, the swelling indeks increases with the decreasing of the crosslink density. This condition due to the process of vulcanization forming polar bond that has an impact on increasing the resistance of swelling (Yuniari et al., 2013). Crosslink hamper the elongation of rubber induced by swelling. As a result, the diffusion of the solvent into the gap between the molecules becomes difficult, thus decrease the percentage of swelling and prevent the occurrence of the chain termination (Indrajati et al., 2012).

\section{CONCLUSIONS}

This research showed that EV, SEV, and CV vulcanization system performed in a blend of EPDM give varying results on the cure characteristics, mechanical properties and swelling characteristics. EV vulcanization system gives the faster vulcanization time (265 s) and lower delta torque (46.93 kgf.cm) than SEV and CV vulcanization systems. The highest mechanical properties of tensile strength $\left(176.19 \mathrm{~kg} / \mathrm{cm}^{2}\right)$, elongation $(493.33 \%)$ and tear strength $(41.12 \mathrm{~kg} / \mathrm{cm})$ were obtained by EV vulcanization system. While the highest hardness ( 75 shore A) was obtained by SEV vulcanization system. The lowest swelling index $(11.36 \%)$ was achieved by CV vulcanization system. In general, EV vulcanization system 
is better and more suitable than SEV and CV for EPDM. However, if the vulcanizates require high resistance to oil, CV is the most appropriate vulcanization system.

\section{ACKNOWLEDGEMENTS}

The authors thank to the Center for Leather, Rubber and Plastics for the facilities and funding in this study.

\section{REFERENCES}

Ahmed, K., Nizami, S. S., Raza, N. Z., and Shirin, K. (2012). Cure characteristics, mechanical and swelling properties of marble sludge filled EPDM modified chloroprene rubber blends. Advances in Materials Physics and Chemistry, 2(2), 90-97, http://dx.doi.org/10.4236/ampc.2012.22016

Dijkhuis, K. A. J., Noordermeer, J. W. M. \& Dierkes, W. K. (2009). The relationship between crosslink system, network structure and material properties of carbon black reinforced EPDM. European Polymer Journal, 45(11), 3302-3312, http:// dx.doi.org/10.1016/j.eurpolymj.2009.06.029

Formela, K. \& Haponiuk, J. T. (2014). Curing characteristics, mechanical properties and morphology of butyl rubber filled with ground tire rubber (GTR). Iranian Polymer Journal, 23(3), 185-194, http://dx.doi.org/10.1007/s13726-013-0214-7

Hasan, A., Rochmadi, Sulistyo, H. \& Honggokusumo, S. (2012). The effect of rubber mixing process on the curing characteristics of natural rubber. Makara Teknologi, 16(2), 109-115.

Hasan, A., Sulistyo, H. \& Honggokusumo, S. (2011). The Influence of mastication to curing characteristic of natural rubber and physical properties of its vulcanizates. Makara Teknologi, 12(2), 81-85.

Indrajati, I N., Dewi, I. R. \& Irwanto, D. (2012). Pengaruh variasi rasio HAF/SRF terhadap sifat vulkanisat NBR. Majalah Kulit, Karet dan Plastik, 28(2), 59-68, http://dx.doi.org/10.20543/mkkp.v28i2.106

Indrajati, I. N. \& Sholeh, M. (2014). Pengaruh rasio MBTS/ZDEC pada campuran karet alam dan etilen propilen diena yang dibuat dengan teknik kontrol migrasi curatives. Majalah Kulit, Karet dan Plastik, 30(1), 43-52, http://dx.doi.org/10.20543/mkkp.v30i1.124
Li, Z. H., Zhang, J. \& Chen, S. J. (2008). Effects of carbon blacks with various structures on vulcanization and reinforcement of filled ethylenepropylene-diene rubber. Express Polymer Letters, 2(10), 695-704, $\quad$ http://dx.doi.org/10.3144/ expresspolymlett.2008.83

Litvinov, V. M., Orza, R. A., Kluppel, M., Van Duin, M. \& Magusin, P. C. M. M. (2011). Rubber-filler interactions and network structure in relation to stress-strain behavior of vulcanizate, carbon black filled EPDM. Macromolecules, 44(12), 48874900, http://dx.doi.org/10.1021/ma2007255

Minnath,AlMehar,Unnikrishnan, G. \& Purushothaman, E. (2011). Transport Studies of thermoplastic polyurethane/natural Rubber (TPU/NR) blends. Journal of Membrane Science, 379 (1-2), 361-69, http://dx.doi.org/10.1016/j.memsci.2011.06.006

Nabil, H., Ismail, H. \& Azura, A. R. (2013). Compounding, mechanical and morphological properties of carbon-black-filled natural rubber/ recycled ethylene-propylene-diene-monomer (NR/R-EPDM) blends. Polymer Testing, 32(2), 385-393, $\quad$ http://dx.doi.org/10.1016/j. polymertesting.2012.11.003

Yahya, Y. R., Azura, A. R. \& Ahmad, Z. (2011). Effect of curing systems on thermal degradation behaviour of natural rubber (SMR CV 60). Journal of Physical Science, 22(2), 1-14.

Yuniari, A. \& Sarengat, N. (2013). Sifat fisika dan analisa gugus fungsi karet seal O-ring dari bahan termoplastik elastomer nitrile butadiene-rubber (NBR) dan polyvinyl chlorida (PVC). Majalah Kulit, Karet dan Plastik, 29(1), 21-30, http://dx.doi.org/10.20543/mkkp.v29i1.215

Yuniari, A., Sarengat, N., Lestari, S. B. P. (2013). Pengaruh sulphur terhadap sifat fisika campuran pale crepe dan SBR untuk karet tahan panas. Majalah Kulit, Karet dan Plastik, 29(2), 63-68, http://dx.doi.org/10.20543/mkkp.v29i2.181 